\title{
Assessing the impacts of climate change on dependable flow and potential irrigable area using the SWAT model. The case of Maasin River watershed in Laguna, Philippines
}

\author{
Lanie A. Alejo, ${ }^{1}$ Victor B. Ella ${ }^{2}$ \\ ${ }^{1}$ College of Engineering, Isabela State University, Echague, Isabela; ${ }^{2}$ University of the Philippines, Los Baños, \\ Laguna, Philippines
}

\begin{abstract}
Seasonal changes in rainfall and temperature brought about by climate change affect water resources availability for rice production areas. There are currently no published applications of the soil and water assessment tool (SWAT) model on quantified effects of climate variability on irrigation service areas for rice production. The study assessed the impacts of climate change on dependable flow and potential irrigable areas of the Maasin River in Laguna, Philippines. Projected variations of rainfall and temperature in 2020 and 2050 developed using PRECIS model based on special report on emission scenarios were employed. The SWAT model was then used to simulate stream flow for each climate change scenario, from which dependable flows were quantified using flow duration analysis. Diversion water requirements for the rice areas in the watershed were determined using CROPWAT. Based on dependable flows and irrigation demand, the potential irrigable areas were estimated. Calibration and validation of the SWAT model showed satisfactory performance in stream flow simulations. The dependable flow in irrigation systems may decline by more than $50 \%$ in 2020 and by as much as $97 \%$ in 2050 , because of seasonal changes in rainfall. In effect, the potential irrigable area may decrease to less than half of the current service area
\end{abstract}

Correspondence: Lanie A. Alejo, College of Engineering, Isabela State University, Barangay San Fabian, Echague, Isabela, Philippines 3309. E-mail: 1han_1023@yahoo.com

Key words: Climate change; potential irrigable area; SWAT.

Acknowledgements: the authors would like to thank the agencies and projects mentioned in this article, which generously shared their data. This work was supported by the DOST - Engineering Research and Development for Technology, DOST - Science Education Institute and the DOST - Philippine Council for Agriculture, Aquatic and Natural Resources Research and Development.

Received for publication: 30 January 2019

Accepted for publication: 27 April 2019.

CCopyright L.A. Alejo and V.B. Ella, 2019

Licensee PAGEPress, Italy

Journal of Agricultural Engineering 2019; L:941

doi:10.4081/jae.2019.941

This article is distributed under the terms of the Creative Commons Attribution Noncommercial License (by-nc 4.0) which permits any noncommercial use, distribution, and reproduction in any medium, provided the original author(s) and source are credited. depending on the level of greenhouse gases emissions. SWAT water balance projections suggest surface runoff during wet seasons and increase annual groundwater recharge are possible sources of supplemental irrigation. Provisions of suitable storage reservoir facilities and groundwater development projects will alleviate water scarce conditions. The study demonstrated a technique that may be applied in other irrigation systems in the Philippines and in other countries to quantify the effects of climate change on dependable flows and potential irrigable areas. It can serve as an input to water resources planning and policy recommendations for climate change adaptation and risk reduction strategies. This technique can also be used to assess water resources in other perennial rivers and its viability for the development of new irrigation systems in the Philippines.

\section{Introduction}

Crop production systems are largely dependent on climate. A huge part of economic losses in crop production is attributed to climate change and variability. In the Philippines alone, a single event of prolonged drought linked to El Niño in 2010 has resulted to 12 billion pesos (US\$235 million, $1 \mathrm{Php}=\mathrm{US} \$ 51$ ) of economic loss in agriculture, which adversely affected the livelihood of many smallholder farmers. The current trend shows that severe drought occurs in the country every 4 to 5 years, which would mean more potential damages to crop production. Lansigan et al. (2000) concluded that $65 \%, 81 \%$ and $52 \%$ decline in rice yield were experienced in the Philippines due to the strong El Niño events in 1973, 1983, and 1990, respectively. Furthermore, trend analyses of rice yield showed declines for every $1 \square \mathrm{C}$ increase in seasonal mean temperature by $15 \%$ from 1979 to 2003 (Peng et al., 2004) and by $13.7 \%$ from 1970-2005 in the rainfed areas in the country (Roberts et al., 2009). Meanwhile, food security issues have driven many countries to be agriculture competitive and growing population has motivated this sector to improve crop production. The Intergovernmental Panel on Climate Change (IPCC) confirmed that rising temperature is causing more floods and dangerous heat waves in many parts of the world. Based on current trends in fossil fuel burning, there could be temperature increases of $3.7^{\circ} \mathrm{C}$ to $4.8^{\circ} \mathrm{C}$ by the end of the century. According to projections, the Philippine climate will be wetter during wet seasons and drier during the dry seasons in 2020 and 2050. Thus, dependable flow for irrigation purposes may also vary, which will likely affect water supplies in major farm production areas. Many rice areas in the Philippines are already experiencing inadequate available water supply despite abundant annual rainfall amounting to about 2000-mm. Annual rainfall distribution is becoming more variable 
with some periods of the year having a limited downpour, thus, leaving many irrigation systems' service areas undersupplied. During these conditions, crop yield declines and this adversely affects the national targets on agricultural competitiveness and food security agendas.

Irrigation systems' service areas are generally designed based on dependable flows. Many irrigation systems are unable to irrigate their designed service areas due to many factors such as design, social, administrative and the looming issues on climate change. However, information on the reduction of irrigation service areas due to climate change is rather limited in published literature. The present study is an attempt to address this gap using the soil and water assessment tool (SWAT) model with its ability to simulate streamflow. The SWAT model is a process-based watershed-modelling platform that has a continuous development period of more than 30 years which began in the early 1980 s (Gassman et al., 2007). It can spatially simulate land and water processes from sub-daily to annual timescales. Spatial output can vary from hydrologic response unit (HRU) to basin-wide (Srinivasan et al., 1998). It is widely used to estimate the impact of various watershed management on soil erosion, runoff and soil nutrients across soil type, climate and topography (Neitsch et al., 2011). Many studies showed that SWAT has the capability to simulate watershed variables. The bulk of these studies reported that SWAT could accurately simulate stream flow. SWAT has also been extensively used and scientifically accepted for water balance studies, assessments of water quality and plant growth in watersheds. Many conference proceedings and peer-reviewed research articles manifested SWAT's robustness of its application in research. The readily available climate projections brought overwhelming research opportunities in the SWAT scientific community especially in evaluating its effect on stream flow. For example, in Colorado, Kopytkovskiy et al. (2015) reported that an increase in temperature due to climate change would result in an alarming decline in river water level by as much as $70 \%$. In Asia, Reshmidevi et al. (2018) used climate projections from 5 global climate models (GCMs) in India and found from their assessments that there is a marginal reduction in annual stream flow and other water balance parameters in the future because of increasing greenhouse gas emissions. Changes in flow duration curves for each climate projections were also examined and discussed in terms of changes in moderate, high and low flows. However, nothing about dependable flows for irrigation was deliberated. Combalicer and Im (2012) concluded from their study that climate change could significantly affect stream flow especially in lands with special uses in the Philippines. SWAT has also been employed for irrigation studies in agricultural watersheds. Zheng et al. (2010) studied the water balance in an irrigation district in China and found that SWAT is applicable for this purpose. Xie and Cui (2011) did the same with a focus on rice paddies and suggested further testing of the model in such areas. Luo et al. (2008) used SWAT to investigate plant-soil and groundwater interactions and concluded that SWAT's plant and soil water components can still be refined for better simulation outputs.

To date, no study on the use of SWAT model to determine the impact of climate change on irrigation parameters exists in published literature and even in the previous works aforementioned, as well as in the SWAT application reviews of Bressiani et al. (2015) and Gassman et al. (2007). Moreover, there are only few published SWAT related researches in the Philippines and none of them dealt with simulation of climate change impacts on irrigation. This study aimed to quantify the impact of climate change on dependable flows and potential irrigable areas using the SWAT model.

\section{Data and methodology}

\section{The study area}

The study site is a typical agricultural area in the Philippines with abundant annual rainfall with distinct wet and dry seasons. It is flooded when there is sustained and intense rainfall, which normally occurs in the last quarter of the year. However, during dry seasons it experiences a shortage of irrigation supply in the first half of the year. The watershed under study is located in the province of Laguna, Philippines. It covers 3 of the province's municipalities namely Victoria, Pila, and Nagcarlan (Figure 1). It has a catchment area of 5067 hectares that is dominated by rice paddies. The Maasin River Watershed is predominantly croplands. About $40 \%$ of the catchment or 2008 hectares are planted with lowland rice and $41 \%$ with perennial crops. The rice areas are largely dependent on the watershed river for irrigation. The river stretch is $13 \mathrm{~km}$ long with headwaters from the Municipality of Nagcarlan, outlet at Victoria and drains in Laguna Lake.

Mean elevation is 66 meters above mean sea level with maximum and minimum values of 649 and 96 meters, respectively. Soil type ranges from clay, clay loam to loam. Most of the rice areas are clay soils. More than half of the catchment area (66\%) is relatively flat at $0-8 \%$ slopes.

\section{Data requirement of soil and water assessment tool}

SWAT can run at the minimum available data set. The minimum data requirements for SWAT are weather, landuse, soil, and elevation. These data are used to define the hydrologic response units (HRUs) in watersheds. HRUs are parcels of the watershed classified by SWAT based on homogenous landuse, soil type, and slope. It is the smallest unit for analysis in SWAT. Digital elevation model is important for the automatic delineation of a watershed divide. SWAT also uses DEM to draw the streams and flow accumulations. It is also the basis to calculate some watershed parameters such as sub-basin area, stream length, channel slope, and others. Many areas in the Philippines have limited to almost no hydrological information that is important for the proper assessment of irrigation sources thereby implicating difficulty in irrigation sustainability planning. The area, for example, does not have observed data on stream flow, evapotranspiration, groundwater data that are fundamental in water balance studies. Researchers in the Philippines also recognised the same problem for their studies (Palao et al., 2013; Briones et al., 2016). Investing in data monitoring systems for these parameters are costly and requires years to gather enough data for reliable studies. To augment lack of data, many researchers published various methods for estimating these data with results acceptable to the scientific community. They are used for policy recommendations, management decisions and climate change assessments. This study applied some of these techniques that will be described in the succeeding sections.

\section{Data sources and pre-processing}

The study area does not have long-term observed data that is essential for calibrating and validating SWAT. Data resources, however, are available in locations within 16 kilometres from the study site. The weather data was taken from the University of the Philippines, Los Baños (UPLB) agrometeorological station, 6 kilometres from the area. Among the weather parameters, rainfall is the most variable in time and space and probably the most important in hydrology. The World Meteorological Organisation suggested that the radius of influence of rain gauges is 25 kilometres, which 
qualify the rainfall input to the model. Moreover, Valencia et al. (2015) reported from their study that rainfall has a radius of influence from 6 kilometres for daily scales to 15 kilometres for annual data. Soil map from the Bureau of Soil and Water Management (BSWM) was considered in the study. It was validated on the ground using soil samples from rice paddies. These areas were considered important for soil verification since the focus of the study is potential irrigable areas. Land use is a result of reclassified land cover map, which was sourced out from the National Mapping and Resource Information Authority (NAMRIA). All the inputs were prepared in consonance to the format required in SWAT. The daily weather data was saved as txt files individually for rainfall, maximum and minimum temperature, relative humidity, wind speed and solar radiation following the default units in SWAT. A weather station with monthly values of the weather parameters was created in the weather user database of SWAT. The Philippine-California Advanced Research Institute (PCARI) project in UPLB provided the soil physical data. It was added in the SWAT database and linked to the soil map of the BSWM. The land cover data from NAMRIA was reclassified into landuse written with codes recognise in SWAT database. Digital elevation model requested from the Integrated National Watershed Research and Development (INWARD) project funded by the Philippine Council for Agriculture, Aquatic and Natural Resources Research and Development (PCAARRD) was a primary input for watershed, sub basin and stream delineation.

Stream flow is an important parameter for agriculture planning. It warrants planners to assess the sustainability of water supply to improve production. Monitoring this parameter, therefore, is important. However, the study area does not have gauging stations
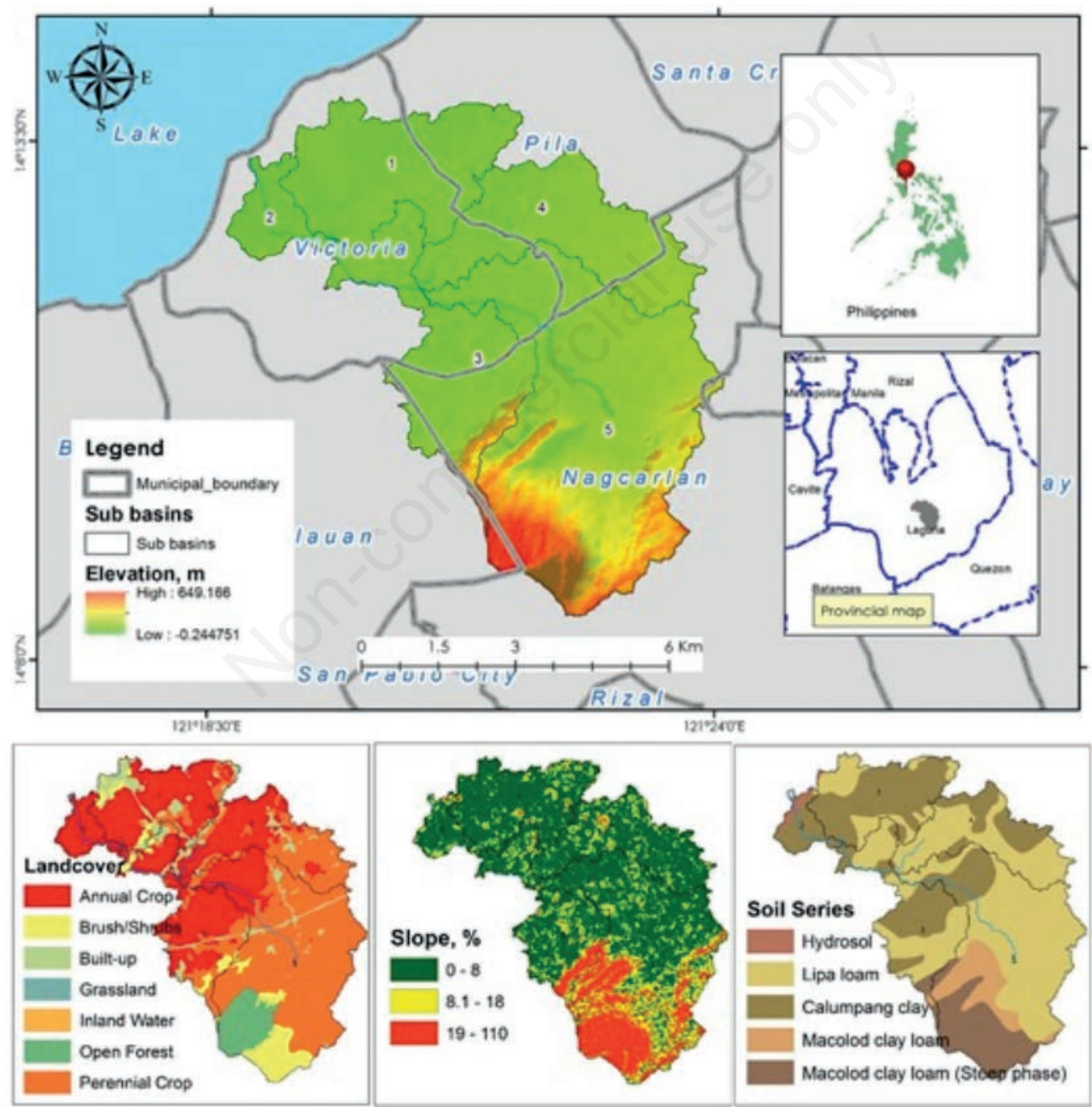

Figure 1. Location, land cover, slope and soil map of the Maasin River watershed. 
to monitor the river flow. Various studies proposed different methods to estimate this parameter. Time series models such as Markov and autoregressive moving average were found relatively adequate in some studies to generate synthetic time series data like stream flow (Akintuğ and Rasmussen, 2005). These models are conventional. However, long-term stream flow data are needed to generate synthetic data.

Many simulation research works did not calibrate their SWAT models against observed variables. For example, Tolentino and Ella (2016) and Swain and Jha (2015) simulated ungauged river catchments and compared the results from manually computed runoff values from water balance and SCS-Curve. Number equations taking into considerations physical characteristics of the watershed. Sanborn and Bledsoe (2006) estimated the stream flow of ungauged streams through stratifying streamflow regimes of gauged rivers. The present study preferred to calibrate the Maasin River watershed using the available long-term observed streamflow from the nearby watershed. Area ratio method was used since it is an acceptable technique to generate streamflow, which is recommended for watersheds with similar hydro climatic conditions. Area ratio method is an interpolation technique using streamflow data from nearby and similar watersheds as reference. Gianfagna et al. (2015) assessed the applicability of this method and found that it accurately estimated daily streamflow. Streamflow used for calibration in this study was based on a gauging station 16 kilometres away from the Maasin River watershed.

\section{Soil and water assessment tool model set up}

With the pre-processed data, the SWAT model for the Maasin River watershed was set up and initially simulated in preparation for calibration. Watershed delineation for predominantly flat areas was observed to produce virtually wrong location of streams, which could yield erratic simulation outputs. SWAT has a limitation on the accurate automatic extraction of the watershed and reaches for flat areas. Luo et al. (2011) described an effective technique to address this within SWAT capabilities. The present study employed this technique. The stream was first delineated based on the Google earth and then verified in the field. Interviews with locals were also conducted to trace the headwaters. The actual stream layout was entered in the Burn-In option under the SWAT watershed delineation window. After which, SWAT delineated the sub basins of the Maasin River watershed. The outlet of the watershed was manually chosen. A threshold of 700 hectares for delineation of sub-watersheds was keyed and thereby generating five sub basins with complete topographic reports and parameters.

HRUs were defined through inputting landuse, soil and keying multiple slope categories. Slopes were categorised into flat to nearly flat (0-3\%), gently sloping (4-8\%), rolling (9-18\%) and steep to very steep $(>18 \%)$. SWAT delineated the slopes based on the DEM. This step yielded 164 HRUs.

Each of the weather parameters' txt file was then inputted in the Write Input Tables window of SWAT and by then the SWAT model for Maasin River Watershed was ready to initialise. Skip year was set to 4 years and outputs were set to monthly. Water balance components of the watershed are the main output parameters. Simulations were saved in preparation for calibration.

\section{Calibration and validation process}

For calibration, SWAT-CUP was preferably employed since it is widely used and recommended by many researchers. It was then set up for streamflow calibration. Prior to setting up, the SWAT initial result for the watershed under study was chosen in SWAT-CUP for calibration. Subsequently, calibration parameters were chosen, beginning and ending of the simulation were assigned and observed streamflow from the area ratio method was stored in the calibration platform. In addition, extraction files were defined. Here, parameters that have to be the basis of SWAT-CUP for calibration are assigned from the SWAT initial simulation results. Also, objective functions are defined. NSE was preferably used and a value of 0.5 was considered. The calibration was set to run for 2000 simulation. Monthly mean streamflow of 8 years (1990 to 1997) was used for calibration. The SWAT calibrated parameters were maintained to simulate streamflow for 7 years from 1998 to 2004 for validation. Statistical indicators for model performance evaluation were selected based on the recommendations of (Moriasi et al., 2007). The coefficient of determination ( $\left.\mathrm{R}^{2}\right)$, NashSutcliffe model efficiency (NSE), root mean square error (RMSE)observations standard deviation ratio (RSR), and percent bias (PBIAS) are the most widely used indicators for assessments. $\mathrm{R}^{2}$ describes the ratio of the variance in observed data explained by the model. Its value ranges from zero to one, with higher values indicating less error variance, and typically values greater than 0.5 are considered acceptable. The NSE is a normalised statistic that defines the relative magnitude of the residual variance compared to the observed data variance. NSE of greater than 0.5 is widely considered satisfactory. RSR is the ratio between RMSE and the standard deviation of the observed values. Zero RSR means there is no error and the model is perfect for simulations. A lower RSR value generally means better simulation results. PBIAS measures the average tendency of the simulated data to be larger or smaller than their observed counterparts. A PBIAS of $+/-25 \%$ is considered satisfactory.

\section{Scenarios building}

Scenario analysis was used to evaluate the impacts of climate variability potential irrigable areas. These scenarios are based on the climate projections published by the Department of Science and Technology-Philippine Atmospheric, Geophysical and Astronomical Services Administration (DOST-PAGASA). They used the Providing Regional Climates for Impact Studies model, which has a resolution 25 by 25 square kilometres. The resolution is relatively coarse, however, from the justification provided in section 0 for the rainfall data; this is already eligible for the study.

Climate change in this study is characterised by changes in rainfall and maximum and minimum temperature. All the parameter changes in the scenarios were based on the historical weather data in the area. Climate scenarios considered were medium-range and high-range emissions for 2-time frames, 2020 (2006-2035) and 2050 (2036-2065). They represent medium and high greenhouse gas levels in the future if there will be no management interventions made at present and increasing emission trends will be sustained. The medium-range scenario represents a carbon dioxide $\left(\mathrm{CO}_{2}\right)$ level that is projected to reach $703 \mathrm{ppm} \mathrm{CO}$ level in 2100 and the high-range scenario up to $836 \mathrm{ppm}$. These scenarios were primarily chosen for the study since according to DOST-PAGASA, these would likely to happen in the future. Medium-range emission scenarios were based on the historical trends and the high-range was developed for impacts and adaptation point of view. The IPCC developed and published the level of emission scenarios in its Special Report on Emission Scenarios. Many modellers adapt it across the world. Percent changes in rainfall and increase in temperatures for the scenarios under the 2 periods are shown in Table 1. The impacts of these projected changes in rainfall and temperature to dependable flow and potential irrigable area were simulat- 
ed. These values are the 30-year average changes for two-time slices 2020 (2006-2035) and 2050 (2036-2065). A substantial decline in rainfall can be observed during the first 2 quarters and a relatively small increase in the last quarter in both periods. Temperature, both maximum (Tmax) and minimum (Tmin), keeps on increasing across scenarios especially in the mid part of the years. Values of rainfall and temperatures in 2020 and 2050 were adjusted based on the local baseline data in the area and then inputted in SWAT weather user database. This was made to downscale the changes and account for variability in climate in the case study area. SWAT weather generator was used for projecting climate base from the monthly averages values.

\section{Determination of dependable flow}

Dependable flows were determined for each scenario. It is the stream flow at $80 \%$ probability of overflow taken from the flow duration curve based on simulation outputs. Normal, Lognormal, Log Pearson and Gumbel distribution probability functions were evaluated for the best fitting of the simulated streamflow data. The best-fit function was used to determine the dependable flow for each scenario. There are also computer platforms available that can be downloaded online. The adequacy of the time series data was also assessed using the minimum time series data equation;

$x_{\min }=\left(4.3 t_{10} \log R\right)^{2}+6$

The minimum data is a function of the value of the $t$ distribution of $10 \%$ level of significance $\left(\mathrm{t}_{10}\right)$ at $(\mathrm{N}-6)$ degrees of freedom and the ratio of the magnitude of the 100-year event to the 2-year event, (R).

\section{Calculation of potential irrigable area}

The potential irrigable area is the ratio of the dependable flow to the diversion water requirement. The dependable flow was derived from SWAT streamflow outputs as described in Section 0 and the diversion water requirement computed from the farm water requirement result of CROPWAT. These were determined for the baseline and all the scenarios. Changes relative to the baseline were quantified as the impacts of climate on the potential irrigable area. CROPWAT was used to establish the irrigation supply scheme of the rice-rice cropping pattern. It is a computer-based tool developed by the Food and Agriculture Organisation (FAO) for quantifying crop water requirement and irrigation scheme supply. It also provides the irrigation water requirement at the farm level. Tibebe et al. (2016) also used CROPWAT in estimating crop water demand and SWAT for runoff approximation but they focused on supply and demand deficit assessments in their study area, which relatively differs from the present study.

The data input includes the baseline rainfall and climate, soil, crop management, and crop coefficients. Planting was set to the actual planting periods in the study area, which is January for dry season and July for the wet season. The established irrigation application efficiency was $70 \%$, which is suitable for planning purposes. To compute for the diversion water requirement, a conveyance efficiency of $80 \%$ was used.

\section{Results}

\section{Calibration and validation}

Both calibration and validation of the Maasin River watershed using streamflow yielded a satisfactory result (Figure 2). Calibration process had $0.82 \mathrm{R}^{2}, 82 \%$ NSE, 0.024 RSR and $-3.7 \%$ PBIAS while validation had $0.73 \mathrm{R}^{2}, 71 \%$ NSE, $0.004 \mathrm{RSR}$ and $5 \%$ PBIAS. These suggest that the model can adequately simulate streamflow of the river. Briones et al. (2016) also plausibly calibrated and validated a SWAT model in Palico River watershed in the Philippines using observed streamflow. These suggest that SWAT is applicable for streamflow simulations in Philippine watershed conditions. Their model also had a lower performance during the validation period relative to the calibration period; however, the validation of the model in this study had better results. The slight changes in land cover in the watershed may have been contributed to this result. In addition to this, the watershed in this study is more than 4 times smaller compared to the Palico River

Table 1. Projected average changes in rainfall and temperature for 2020 and 2050 in the study area.

\begin{tabular}{|c|c|c|c|c|}
\hline Scenarios & Quarter & Rainfall, \% & $\mathrm{Tmax},{ }^{\circ} \mathrm{C}$ & $\operatorname{Tmin},{ }^{\circ} \mathrm{C}$ \\
\hline \multicolumn{5}{|l|}{2020} \\
\hline High-range emission scenario & $\begin{array}{c}\text { DJF } \\
\text { MAM } \\
\text { JJA } \\
\text { SON }\end{array}$ & $\begin{array}{c}-31.6 \\
-9.8 \\
10.7 \\
0\end{array}$ & $\begin{array}{l}0.4 \\
0.8 \\
0.5 \\
0.6\end{array}$ & $\begin{array}{l}0.6 \\
0.8 \\
0.8 \\
0.7\end{array}$ \\
\hline Medium-range emission scenario & $\begin{array}{c}\text { DJF } \\
\text { MAM } \\
\text { JJA } \\
\text { SON }\end{array}$ & $\begin{array}{c}-20.2 \\
-31.5 \\
2.9 \\
2\end{array}$ & $\begin{array}{c}1 \\
1.3 \\
0.9 \\
1\end{array}$ & $\begin{array}{c}0.9 \\
1.1 \\
1.2 \\
1\end{array}$ \\
\hline \multicolumn{5}{|l|}{2050} \\
\hline High-range emission scenario & $\begin{array}{c}\text { DJF } \\
\text { MAM } \\
\text { JJA } \\
\text { SON }\end{array}$ & $\begin{array}{c}-31 \\
-21.3 \\
0.3 \\
2.1\end{array}$ & $\begin{array}{l}1.3 \\
1.8 \\
1.7 \\
1.6\end{array}$ & $\begin{array}{l}1.5 \\
1.9 \\
1.9 \\
1.7\end{array}$ \\
\hline Medium-range emission scenario & $\begin{array}{c}\text { DJF } \\
\text { MAM } \\
\text { JJA } \\
\text { SON }\end{array}$ & $\begin{array}{l}0.1 \\
-34.8 \\
6.8 \\
0.4\end{array}$ & $\begin{array}{c}2 \\
2.4 \\
1.7 \\
2\end{array}$ & $\begin{array}{l}1.8 \\
2.1 \\
2.3 \\
1.9\end{array}$ \\
\hline
\end{tabular}

DJF, December, January and February; MAM, March, April and May; JJA, June, July, and August; SON, September, October, and November. 
watershed with a catchment area of 23, 691 ha. Future calibration and validation studies in data-limited areas may be improved using satellite data. Parameters calibrated and their corresponding fitted values are shown in Table 2.

\section{Projected mean annual and monthly streamflow}

Mean annual streamflow is highly affected by climate change due to increase in temperature and decreased rainfall. It is projected to decrease by half under medium range scenario in 2020 and there will only be $5 \%$ streamflow left relative to the present conditions by 2050 in the medium range and in the 2 high range scenarios (Figure 3). This shows that further increase in greenhouse gas emissions will dry up the Maasin River, which would leave many rice areas under water stress conditions assuming that the crop

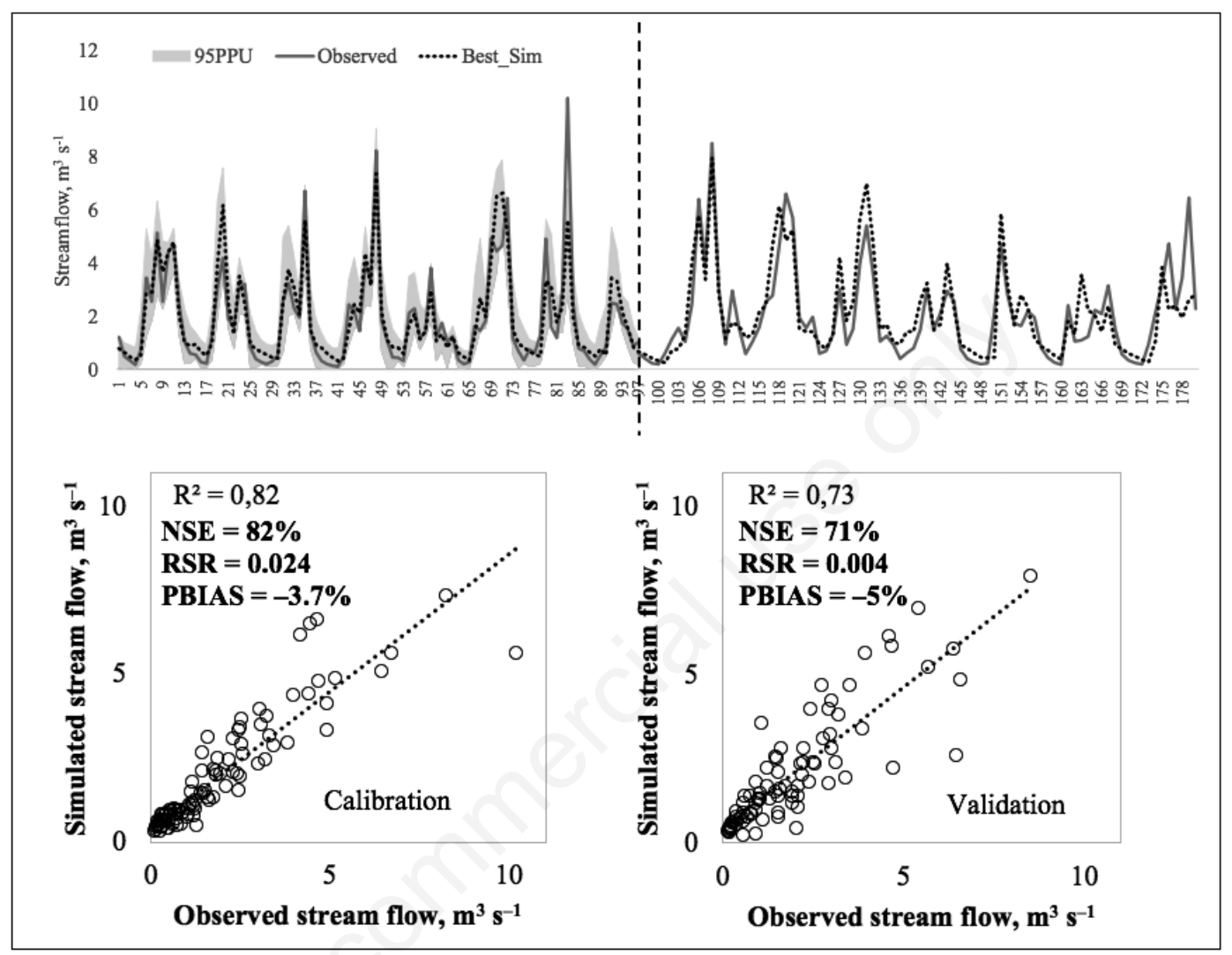

Figure 2. Statistical indices that show the goodness of fit between the observed and simulated stream flow during the calibration and validation processes.

Table 2. Calibrated SWAT parameters for the Maasin River watershed.

\begin{tabular}{|c|c|c|c|c|}
\hline Parameter name & Description & Fitted value & Minimum value & Maximum value \\
\hline 1 R_CN2.mgt & Initial SCS CN II value & 0.0709 & -0.2 & 0.2 \\
\hline 2V_ALPHA_BF.gw & Base flow alpha factor [days] & 0.52575 & 0 & 1 \\
\hline 3V_GW_DELAY.gW & Groundwater delay [days] & 230.024994 & 30 & 450 \\
\hline $4 \mathrm{~V} \_$GWQMN.gW & $\begin{array}{l}\text { Threshold depth of water in the shallow aquifer } \\
\text { required for return flow to occur [mm] }\end{array}$ & 0.8775 & 0 & 2 \\
\hline 5V_GW_REVAP.gW & Groundwater revap coefficient & 0.12955 & 0 & 0.2 \\
\hline 6 V_ESCO.hru & Soil evaporation compensation factor & 0.91875 & 0.8 & 1 \\
\hline 7 V__OV_N.hru & Manning's $n$ value for overland flow & 12.298403 & 0.01 & 30 \\
\hline 8 V__CH_N2.rte & Manning's $n$ value for main channel & 0.012225 & 0 & 0.3 \\
\hline 9 V_CH_K2.rte & Effective hydraulic conductivity [ $\left.\mathrm{mm} \mathrm{hr}^{-1}\right]$ & 96.78125 & 5 & 130 \\
\hline 10V_ALPHA_BNK.rte & Base flow alpha factor for bank storage [days] & 0.02625 & 0 & 1 \\
\hline 11R_SOL_AWC(..).sol & Available water capacity of the soil layer, $\mathrm{mm} / \mathrm{mm}$ & 0.21985 & -0.2 & 0.4 \\
\hline 12R_SOL_K(..).sol & Saturated hydraulic conductivity, $\mathrm{mm} \mathrm{h}^{-1}$ & -0.3444 & -0.8 & 0.8 \\
\hline 13R_SOL_BD(..).sol & Moist bulk density, $\mathrm{g} \mathrm{cm}^{-3}$ & -0.391375 & -0.5 & 0.6 \\
\hline
\end{tabular}

$\mathrm{r}$, existing parameter value is multiplied by (1+ given value); $v$, existing parameter value is to be replaced by given value. 
management being employed today will be the same across scenarios. Mean monthly flows, however, increased starting July to October and declined from November to June in the 2020 mediumrange scenario. This can be attributed to the increase in rainfall in the $3^{\text {rd }}$ quarter of the year and large decrease within the first 2 quarters. Rainfall plays a big role in streamflow changes, streamflow increases with rainfall. A similar trend was discussed by Tan et al. (2017) in India. With further increase in GHG in 2050 medium range and for both periods in high range emissions, monthly mean flows decline throughout the year. This result can be due to increasing temperature and thus evapotranspiration increases. This is coupled with a substantial reduction in rainfall in high range scenario by as much as $31 \%$ in the first quarter and $21 \%$ in the $2^{\text {nd }}$ quarter of the year. In the 2050 medium range scenario, the largest decline in rainfall falls during the $3^{\text {rd }}$ quarter of the year.

\section{Projected dependable flows}

Log Pearson probability distribution function had the best fit for the discharge data (not shown). It was then employed to determine the mean annual dependable flow for the period 1990 to 2004. Similarly, the dependable flow for each scenario and time frame were determined. The computed minimum data using Equation (1) was 7 years, which means that the 15-year data used in this study is more than enough for water resources studies.

Dependable flows of $80 \%$ probability of overflow are projected to decline considerably by more than $50 \%$ when emissions are at the medium range in 2020 (Figure 4). Projections showed that there would only be $3 \%$ of dependable flow left relative to the baseline in 2050 medium range emissions and in both time frames in high levels of emissions. The flow duration curves of 2050 medium range, 2020 high range, and 2050 high followed the same trend and thus overlapped. This suggests that a further increase in levels of greenhouse gases (GHG) emissions beyond the levels of medium range in 2020 will leave the rivers' source of water unreliable for irrigation.

\section{Potential irrigable area}

CROPWAT computes the largest deficit in rainfall during the month of June thereby needing more irrigation supply (Figure 5). This is attributed to high water requirement during land soaking and land preparation for wet cropping season. The soil during this month is relatively dry because it immediately follows the dry season. The residual moisture content from the dry season is very low thereby higher water demand. On the other hand, there are no rainfall deficits in the months of May and July to November. Fallow period falls in May and November while rainfall is very much abundant from July to October. The farm water requirement appropriately considered was taken from the month of June amounting to $1.38 \mathrm{lps} \mathrm{ha}^{-1}\left(0.00138 \mathrm{~m}^{3} \mathrm{~s}^{-1}\right)$.

The computed DWR based on the farm water requirement was $1.73 \mathrm{lps} \mathrm{ha}^{-1}\left(0.00173 \mathrm{~m}^{3} \mathrm{~s}^{-1}\right)$. With this, the potential irrigable area for a dependable flow of $1.48 \mathrm{~m}^{3} \mathrm{~s}^{-1}$ in the reference scenario taken from Figure 4 was found to be 855 hectares only (Table 3 ). This means that the dependable flow in the Maasin River is not enough to irrigate the actual area of 2008 hectares. This suggests the need for other water resource development such as rainwater

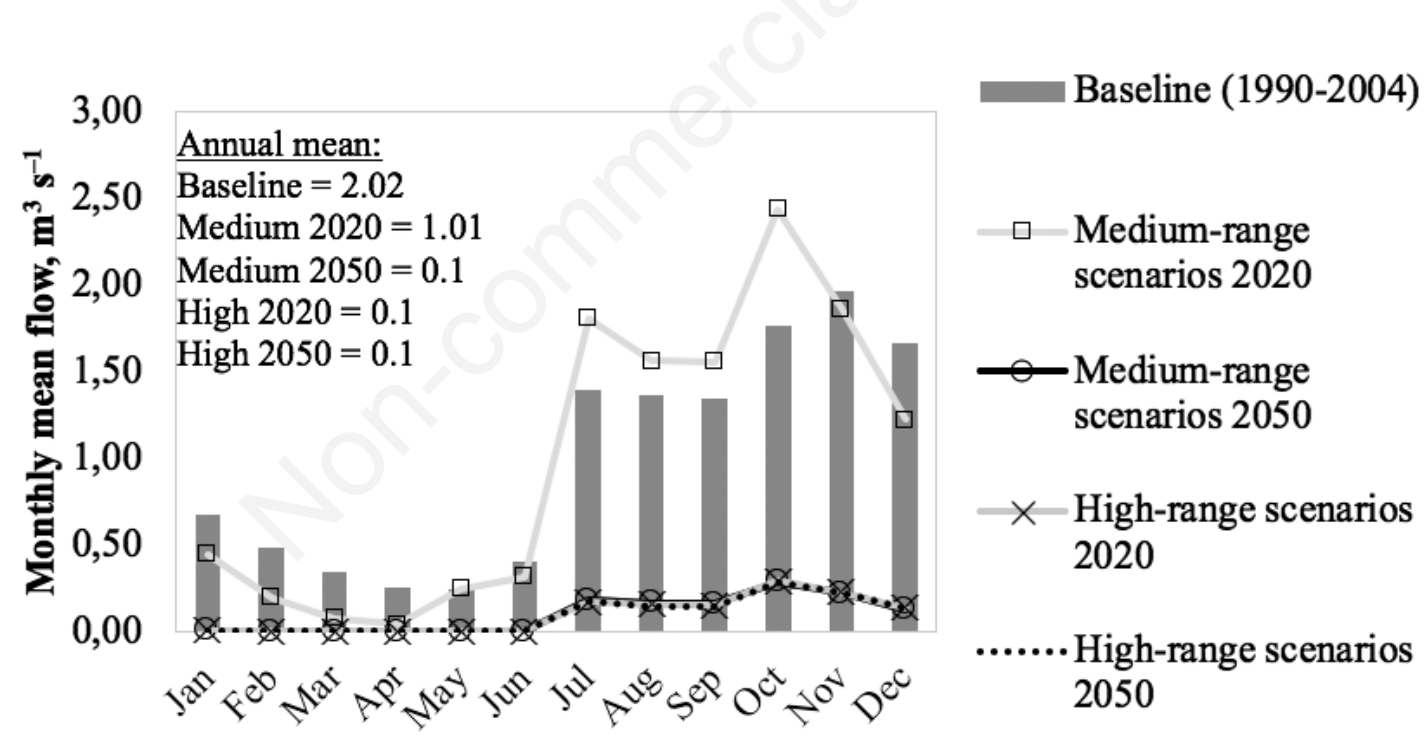

Figure 3. Mean annual and monthly streamflow. Note that the lines for 2050 medium range, 2020 high range, and 2050 high range almost overlapped.

Table 3. Projected potential irrigable area.

\begin{tabular}{|c|c|c|c|c|}
\hline Scenario & & Dependable flow, $\mathrm{m}^{3} \mathrm{~s}^{-1}$ & Water duty, lps ha-1 & Potential irrigable area, ha \\
\hline Baseline & & 1.48 & 1.73 & 855 \\
\hline Medium-range & $\begin{array}{l}2020 \\
2050\end{array}$ & $\begin{array}{l}0.61 \\
0.05\end{array}$ & $\begin{array}{l}1.73 \\
1.73\end{array}$ & $\begin{array}{c}353 \\
29\end{array}$ \\
\hline High-range & $\begin{array}{l}2020 \\
2050\end{array}$ & $\begin{array}{l}0.049 \\
0.048\end{array}$ & $\begin{array}{l}1.73 \\
1.73\end{array}$ & $\begin{array}{l}28 \\
28\end{array}$ \\
\hline
\end{tabular}


harvesting or groundwater. The SWAT simulation results showed high runoff during wet seasons and a considerable amount of annual recharge. Furthermore, results also showed that there is a considerable reduction in the potential irrigable area by 57 to $97 \%$. This is largely due to changes in rainfall and temperature brought by the increase in greenhouse gas emissions. Diversion water requirements used were assumed the same across scenarios to sim- ulate most of the irrigation systems' operational and management practice of not updating these requirements.

\section{Other potential sources of irrigation supply}

With decrease trends of dependable flows simulated in the Maasin River, SWAT results showed other potential sources for supplemental irrigation particularly helpful for dry seasons.

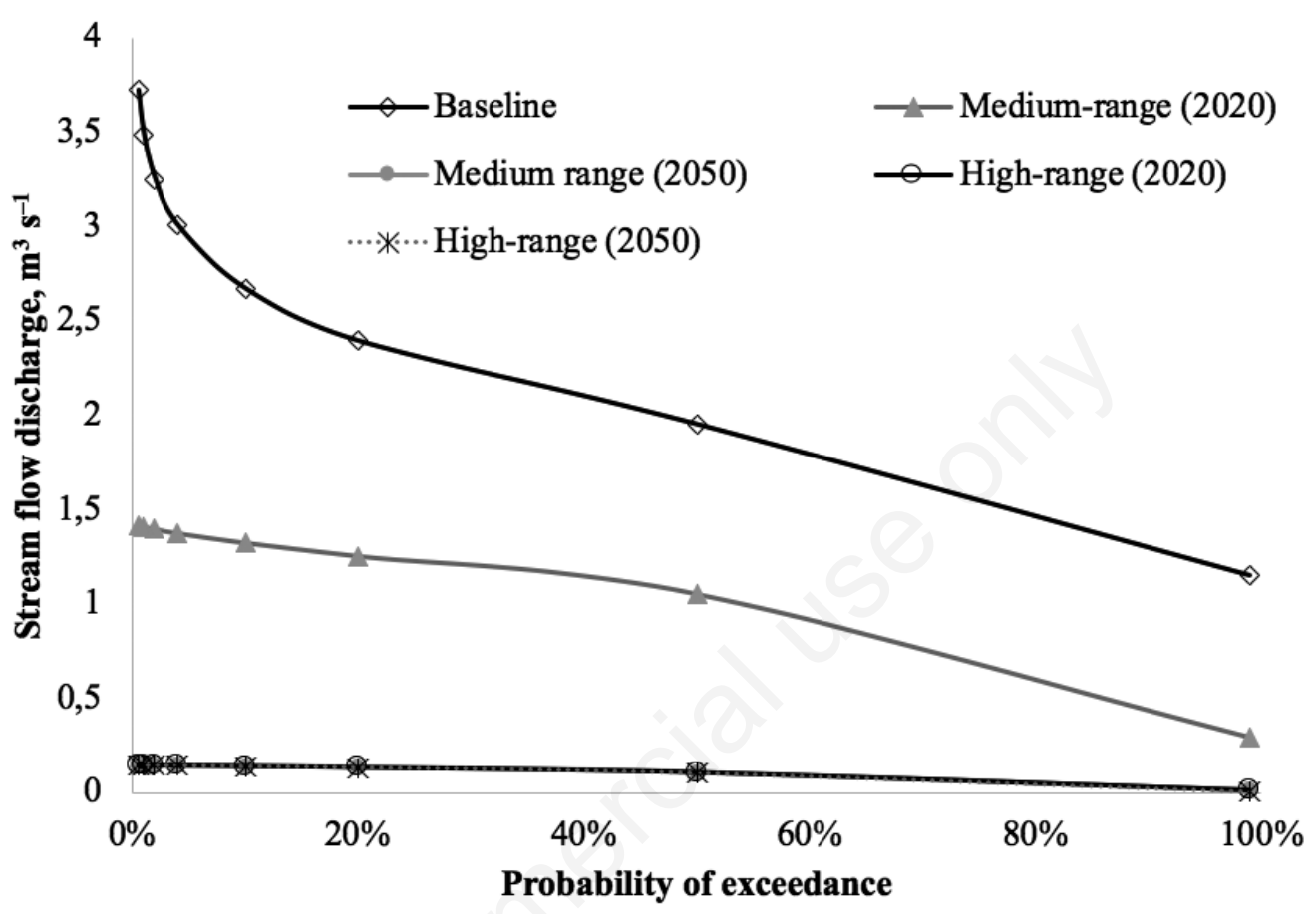

Figure 4. Flow duration curves for baseline and all scenarios. Note that the curves for 2050 medium range, 2020 high range, and 2050 high range had the same trend and thus overlapped.

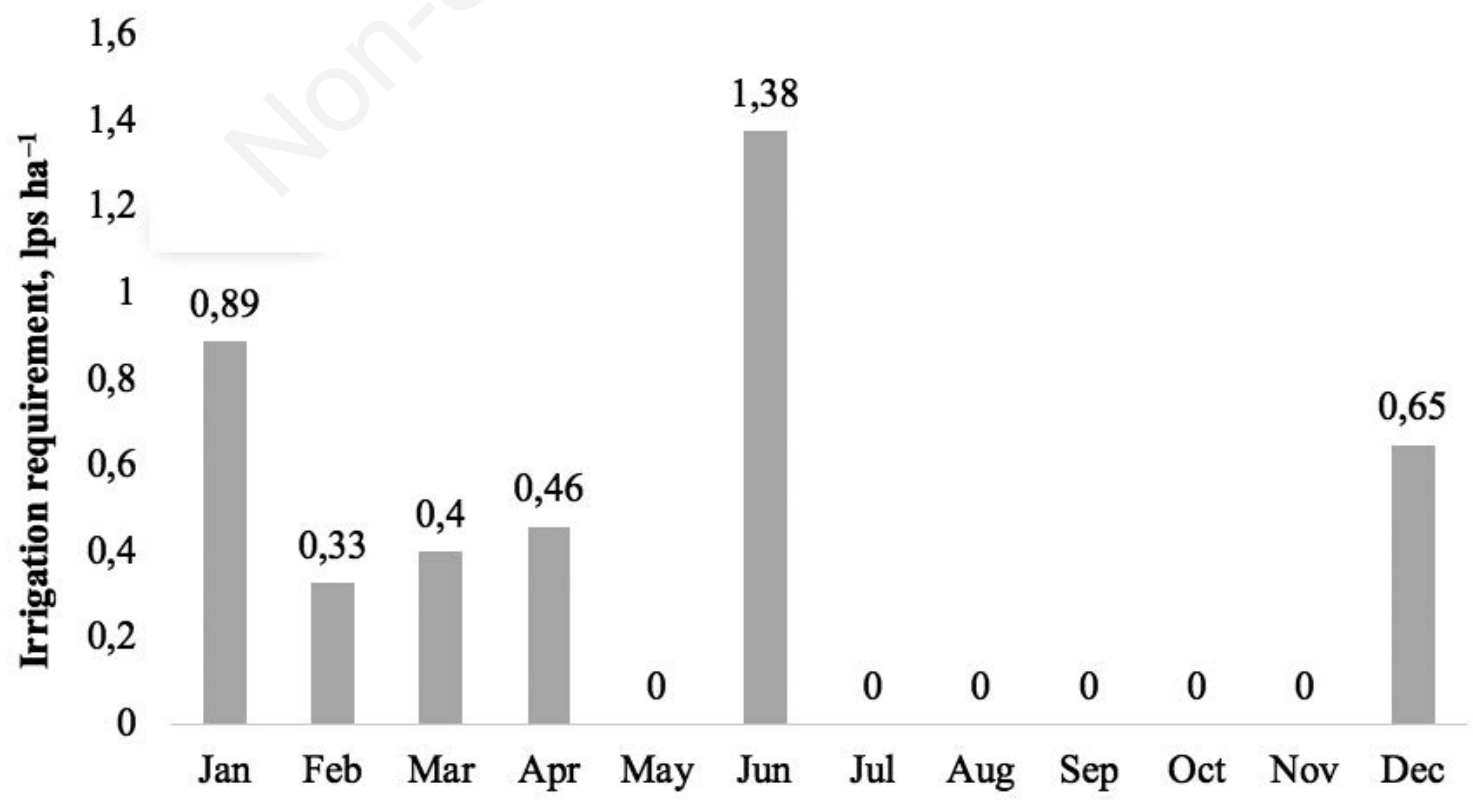

Figure 5. Irrigation water requirement for the rice-rice cropping pattern. 
Surface runoff is sustained in all the scenarios with a relatively moderate decrease from 16 to $22 \%$ except for 2050 high range scenarios (Figure 6). It had a large decline of about $82 \%$ relative to the baseline scenario. The lowest runoff in 2050 high-range emission scenario amounting to $157.19 \mathrm{~mm}$ is equivalent to almost 9 million cubic meters of water collected from the 5067 hectares catchment area. This only shows that reservoirs are a promising development project, which could serve as a source for supplemental irrigation for dry seasons. It will also be an important facility for flood mitigation. Moreover, it is being used as groundwater recharge in other countries.

In addition, groundwater recharge is likely to increase even with increased GHG emissions (Figure 7). From the water balance results, percolation out of soil was the most contributing factor in

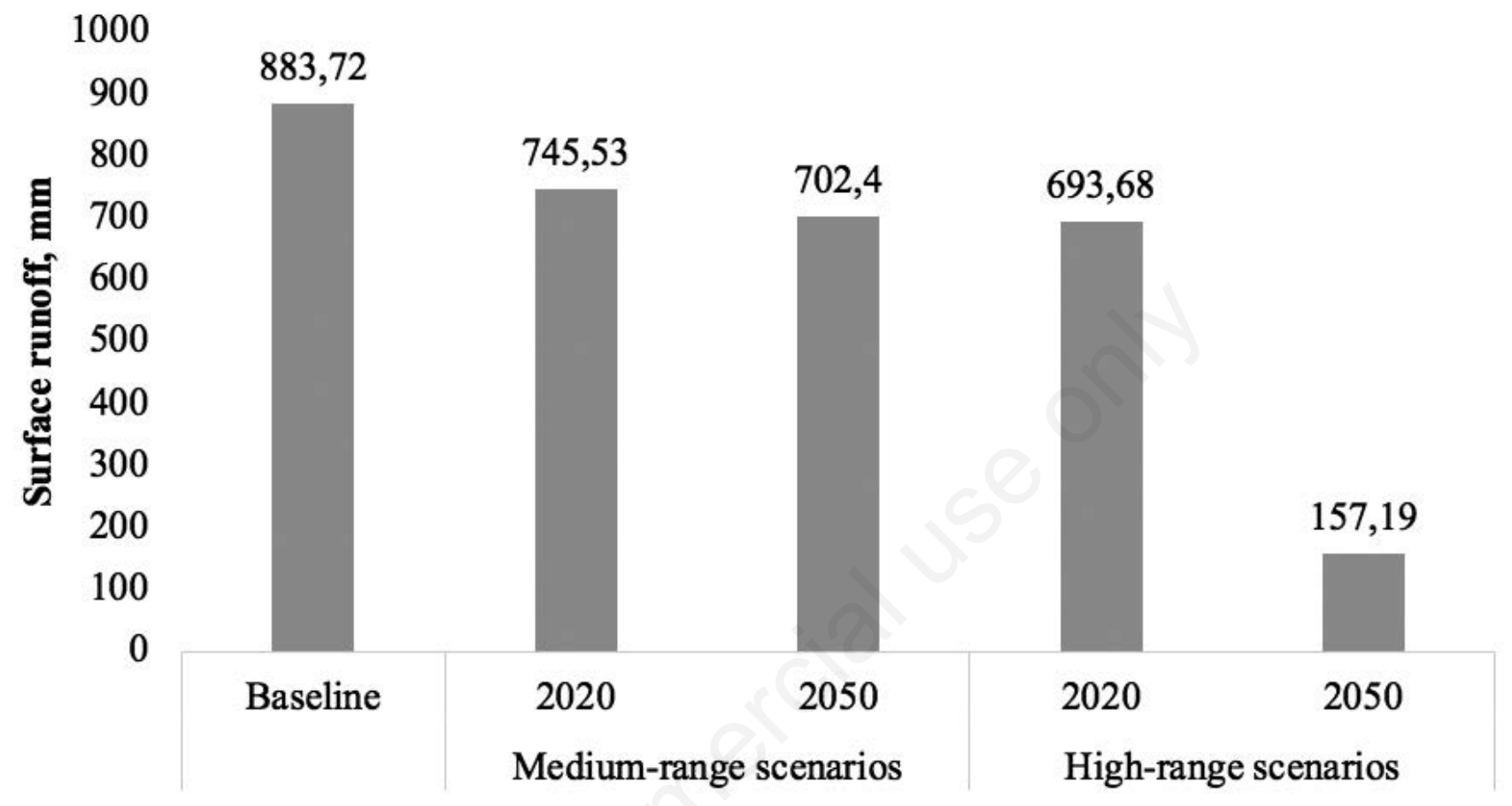

Figure 6. Projected surface runoff for the baseline and all scenarios, $\mathrm{mm}$.

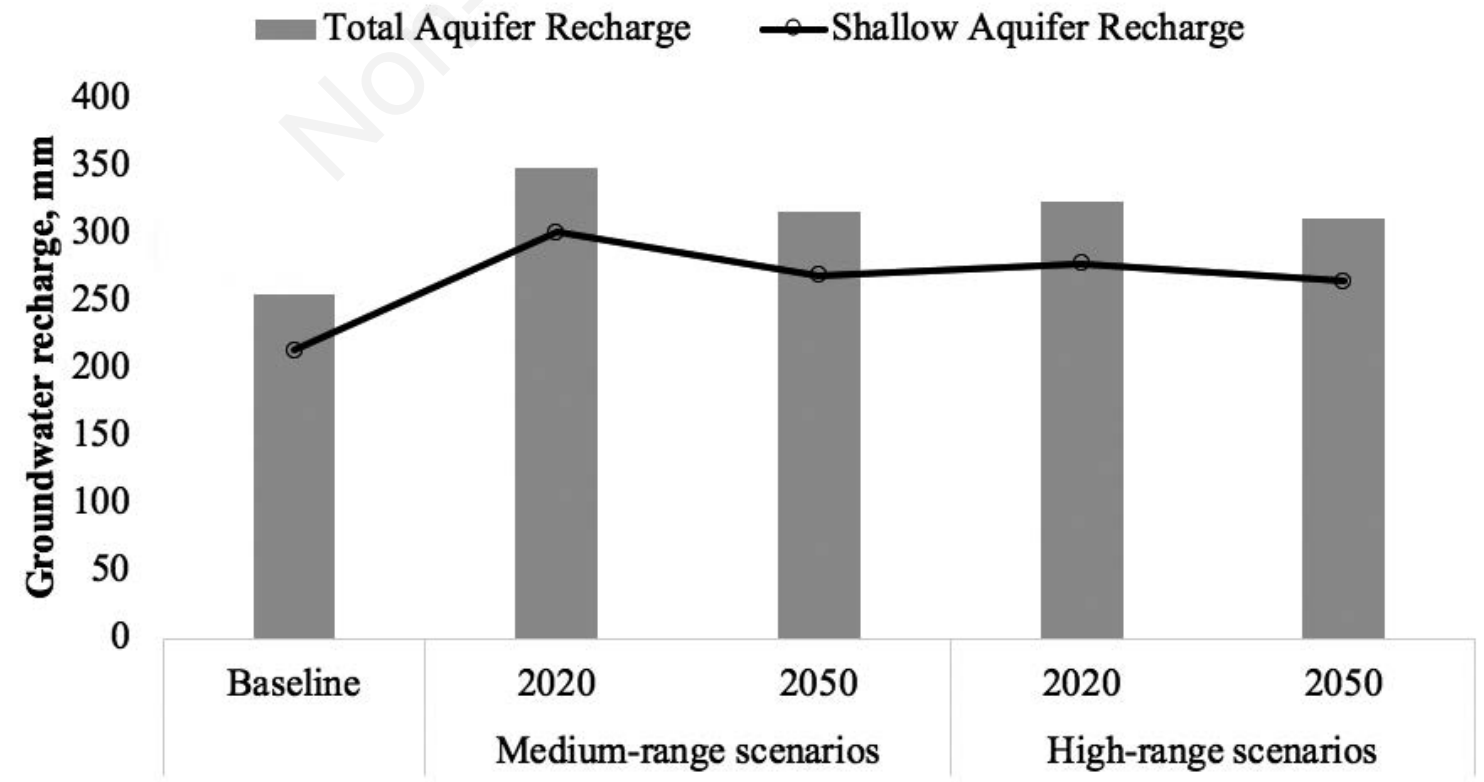

Figure 7. Projected groundwater recharge for the baseline and all scenarios, $\mathrm{mm}$. 
the variability of groundwater recharge. Awan and Ismaeel (2014) found the same increasing trend in groundwater recharge and reported $40 \%$ and $37 \%$ increase in representative concentration pathways (RCP) 4.5 and RCP 8.5, respectively. These RCP scenarios are also a representation of changes in rainfall and temperature because of GHG emissions. In the present study, the annual recharge of $310 \mathrm{~mm}$ by 2050 in high range emissions is corresponding to an annual supply of 15.7 million cubic meters. Although recharge has an impact on groundwater levels, more importantly, groundwater extractions will definitely have an effect on the actual levels of groundwater in the area. Groundwater levels were not considered in the present study. However, Ella (2011) projected that groundwater levels in the nearby area will likely decline by $0.43138 \mathrm{~m}, 0.45143 \mathrm{~m}$ and $0.45177 \mathrm{~m}$ with a decrease in rainfall of 0,10 , and 20 percent, respectively. Recharge is governed by the conditions above the water table, thus it is independent of groundwater levels. The country has vast groundwater resource that is spatially variable, which can be affected by various factors aside from climate change that may include watershed degradation, population growth, and industrialisation, to name a few. This suggests a thorough investigation of the impacts of these factors on the groundwater resource in the study area.

\section{Conclusions}

The study quantified the impacts of climate change on dependable flows and potential irrigable areas in irrigation systems. Climate change leads to a decrease in potential irrigable area due to a decrease in dependable flow and an increase in irrigation water requirements in the study area, particularly under high emission scenarios. Because of the increasing greenhouse gas emissions brought by rapid industrialisation, there will be a substantial shrinking of irrigable areas in irrigation systems, which may range from $57 \%$ to $97 \%$. This could be a threat to food security in major rice producing areas as well as in the areas dependent on rice importations. SWAT water balance results revealed other potential sources of irrigation supply such as reservoirs for surface runoff and groundwater development projects from aquifer recharge. Further investigations on these potential resources and how they change in the future are suggested. Nevertheless, these results showed an opportunity for improved rice yields amidst climate change. Irrigation expansion and development of new irrigation systems are necessary to ensure food production during extreme climate conditions. Assessment of water resources in other perennial rivers in the country for new irrigation system development can be done using the methodology in this study.

The study presented a useful methodology to assess the impacts of climate change to irrigable areas in irrigation systems to support operation and management decisions for climate change adaptation and risk reduction strategies. This technique can be recommended for use in other irrigation systems in the Philippines and in other countries to evaluate the impacts of climate change in their service areas. Also, it is a useful method in irrigation system planning particularly in setting designed service areas. This way, smallholder farmers suffering from yield and income losses because of drying farms in irrigation systems could be avoided. Factors, other than climate change (e.g. landuse change), which may affect potential service areas in irrigation systems can also be evaluated using the suggested technique. In data challenged watersheds, the supplemental use of satellite data may be explored to improve the calibration and validation of SWAT models.

\section{References}

Akintuğ B., Rasmussen P.F. 2005. A Markov switching model for annual hydrologic time series. Water Resour. Res. 41:1-10.

Awan U.K., Ismaeel A. 2014. A new technique to map groundwater recharge in irrigated areas using a SWAT model under changing climate. J. Hydrol. 519:1368-82.

Bressiani D. de A., Gassman P.W., Fernandes J.G., Garbossa L.H.P., Srinivasan R., Bonumá N.B., Mendiondo E.M. 2015. A review of soil and water assessment tool (SWAT) applications in Brazil: challenges and prospects. Int. J. Agric. Biol. Eng. 8:1-27.

Briones R.U., Ella V.B., Bantayan N.C. 2016. Hydrologic impact evaluation of land use and land cover change in Palico Watershed, Batangas, Philippines Using the SWAT model. J. Environ. Sci. Manag. 19:96-107.

Combalicer E.A., Im S. 2012. Change anomalies of hydrologic responses to climate variability and land-use changes in the Mt. Makiling forest reserve. J. Environ. Sci. Manag. 15:1-13.

Ella V.B. 2011. Simulating the hydraulic effects of climate change on groundwater resources in a selected aquifer in the Philippines using a numerical groundwater model.

Gassman P.W., Reyes M.R., Green C.H., Arnold J.G. 2007. The soil and water assessment tool : historical development, applications, and future research directions. Trans. ASAE 50:1211-50.

Gianfagna C.C., Johnson C.E., Chandler D.G., Hofmann C. 2015. Watershed area ratio accurately predicts daily streamflow in nested catchments in the Catskills, New York. J. Hydrol. Reg. Stud. 4:583-94.

Kopytkovskiy M., Geza M., McCray J.E. 2015. Climate-change impacts on water resources and hydropower potential in the Upper Colorado River Basin. J. Hydrol. Reg. Stud. 3:473-93.

Lansigan F.P., De Los Santos W.L., Coladilla J.O. 2000. Agronomic impacts of climate variability on rice production in the Philippines. Agric. Ecosyst. Environ. 82:129-37.

Luo Y., He C., Sophocleous M., Yin Z., Hongrui R., Ouyang Z. 2008. Assessment of crop growth and soil water modules in SWAT2000 using extensive field experiment data in an irrigation district of the Yellow River Basin. J. Hydrol. 352:139-56.

Luo Y., Su B., Yuan J., Li H., Zhang Q. 2011. GIS techniques for watershed delineation of SWAT model in plain polders. Procedia Environ. Sci. 10:2050-7.

Moriasi D.N., Arnold J.G., Van Liew M.W., Bingner R.L., Harmel R.D., Veith T.L. 2007. Model evaluation guidelines for systematic quantification of accuracy in watershed simulations. Trans. ASABE 50:885-900.

Neitsch S., Arnold J., Kiniry J., Williams J. 2011. Soil and water assessment tool theoretical documentation version 2009. Texas Water Resour. Inst. 1-647.

Palao L.K.M., Dorado M.M., Anit K.P.A., Lasco R.D. 2013. Using the soil and water assessment tool (SWAT) to assess material transfer in the Layawan Watershed, Mindanao, Philippines and Its implications on payment for ecosystem services. J. Sustain. Dev. 6:73-88.

Peng S., Huang J., Sheehy J.E., Laza R.C., Visperas R.M., Zhong X., Centeno G.S., Khush G.S., Cassman K.G. 2004. Rice yields decline with higher night temperature from global warming. Proc. Natl. Acad. Sci. 101:9971-5.

Reshmidevi T.V., Nagesh Kumar D., Mehrotra R., Sharma A. 2018. Estimation of the climate change impact on a catchment water balance using an ensemble of GCMs. J. Hydrol. 556:1192-204. 
Roberts M.G., Dawe D., Falcon W.P., Naylor R.L. 2009. El Niñosouthern oscillation impacts on rice production in Luzon, the Philippines. J. Appl. Meteorol. Climatol. 48:1718-24.

Sanborn S.C., Bledsoe B.P. 2006. Predicting streamflow regime metrics for ungauged streamsin Colorado, Washington, and Oregon. J. Hydrol. 325:241-61.

Srinivasan R., Ramanarayanan T.S., Arnold J.G., Bednarz S.T. 1998. Large Area Hydrologic Modeling and Assessment Part II: Model Application. J. Am. Water Resour. Assoc. 34:91-101.

Swain J.B., Jha R. 2015. Stream flow estimation in an ungauged catchment of Odisha. Int. J. Res. Sci. Innov. 2:9-14.

Tan M.L., Ibrahim A.L., Yusop Z., Chua V.P., Chan N.W. 2017. Climate change impacts under CMIP5 RCP scenarios on water resources of the Kelantan River Basin, Malaysia. Atmos. Res. 189:1-10.

Tibebe M., Melesse A.M., Zemadim B. 2016. Runoff estimation and water demand analysis for Holetta River, Awash Subbasin,
Ethiopia using SWAT and CropWat Models. pp 113-40 in: A.M. Melesse and W. Abtew (Eds.), Landsc. Dyn. Soils Hydrol. Process. Varied Clim. Springer.

Tolentino A.B., Ella V.B. 2016. Assessment of SWAT model applicability and performance for predicting surface runoff in an ungauged watershed in the Philippines. IAMURE Int. J. Ecol. Conserv. 17:142-59.

Valencia J.A., Castillo R O.G., Betancur J.F., Peña A.J. 2015. Influence area determination of rain gauge stations in the coffee region, Caldas department, Colombia. Glob. Adv. Res. J. Agric. Sci. 4:2315-94.

Xie X., Cui Y. 2011. Development and test of SWAT for modeling hydrological processes in irrigation districts with paddy rice. J. Hydrol. 396:61-71.

Zheng J., Li G., Han Z., Meng G. 2010. Hydrological cycle simulation of an irrigation district based on a SWAT model. Math. Comput. Model. 51:1312-8. 